\title{
Etiologia de otitis media aguda purulenta en lactantes
}

\author{
Drs. M. Teresa Siri;*** Antonio Banfi; ${ }^{* *}$ G. Barroilhet; $* * *$ J. C. gatica;**** M. A. Delucchi****
}

\begin{abstract}
A study of acute bacterial otitis was performed in 41 infants.

Streptexuccus pneumomae was the primeipal agent $(48,8 \%)$ and Haemophilus influenzae ulso had an important role.

Tympanocentesis is not mandatory in a child with otitis, except in some special conditions.

The pediatrician knowing the possible etiology can institute a rationale therapy.
\end{abstract}

El cuadro de otitis media aguda representa una condición frecuente en Pediatria.4, 6 Literatura extranjera demuestra, que por lo menos el $25 \%$ de los niños la han experimentado en algún momento de su vida, encontrándose la mayor incidencia en los menores de 2 años $(68 \%))^{1,2}$

Hace ya más de un siglo se describió material purulento en oído medio y sôlo en los últimos años se ha puesto énfasis en aclarar la etiologia y determinar los parámetros clinicos relacionados con este cuadro. $1,4,5,7,8$

En nuestro medio es importante establecer los hallazgos clínicos y agentes etiológicos responsables, ya que disponemos de pocos datos al respecto.

El manejo terapéutico, constituye un problema por la dificultad técnica que representa la obtención de una buena muestra para estudio bacteriológico, sumado al riesgo de secuelas secundarias a la paracentesis sin equipo adecuado. Sin embargo, esta técnica realizada por el especialista y bajo microscopio, no implica mayor riesgo para el paciente.

Conociendo la frecuencia de los agentes patógenos responsables del cuadro, podemos elegir la

* Unidad Microbialogia, División Oriente. Eniversidad de Chile.

"* Uniclad Infecciosos Hospital Luis Calvo Mackenin.

***Servivio Otorrinolaringología Hospital Luís Calvo Mickenna.

$x * *$ Becados Departamento Pexliatria Hospital Luis Cullvo slackenma. terapia más racional prescindiendo de la paracentesis por las razones ya expuestas.

Hemos considerado importante establecer estos parámetros en la otitis media aguda purulenta de los lactantes de nuestro medio.

\section{MATERIAL Y METODO}

Se estudiaron 41 niños cuyas edades fluctuaron entre 1 y 24 meses, que acudieron al Servicio de Otorrino del Hospital Calvo Mackenna con el diagnóstico clínico de otitis media aguda (uno o ambos tímpanos abombados con borramiento de la prominencia de la apófisis corta y mango del martillo).

Se incluyeron pacientes con:

- Otitis supurada con pertoración timpánica.

- Tratarniento antibiótico previo las últimas dos semanas.

En aquellos niños cuyo tímpano presentaba las caracteristicas descritas, se procedió de la siguiente forma:

- Aseo del conducto auditivo externo con agua destilada estéril.

- Paracentesis con aguja de punción en condiciones asépticas.

- Aspiración de secreción con jeringa en condiciones as épticas.

- Siembra inmediata de la muestra en agar chocolate e incubación a $37^{\circ} \mathrm{C}$ en campana de $\mathrm{CO}_{2}$ durante 18-24 hrs.

En nuestra casuistica el mayor número de niños 
se encuentra en los menores de I año, 35 casos de un total de 41 , lo que representa un $85,4 \%$, ubicándose el $58,5 \%$ en los menores de 6 meses.

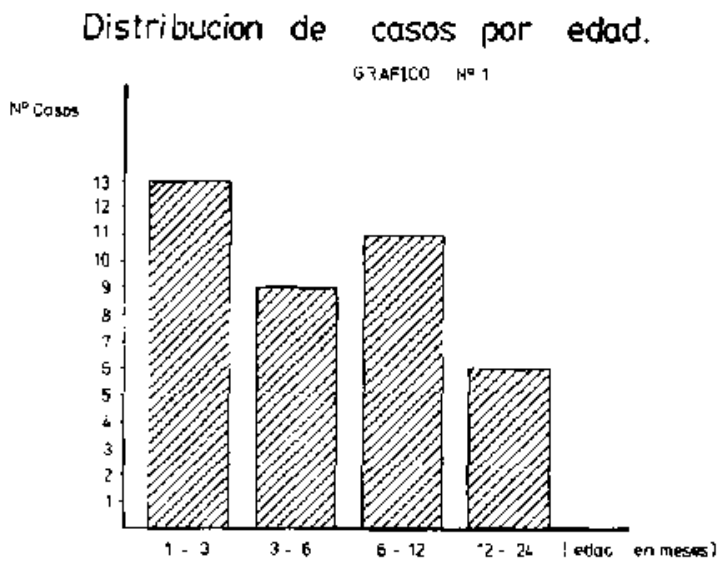

RESULTADOS

Se obtuvo desarrollo bacteriano en 36 del total de las 41 muestras estudiadas, encontrándose la sigujente frecuencia de gérmenes:

Tabla 1

\begin{tabular}{lrr}
\hline & Cusos & $\%$ \\
\hline Streptococeus pneumoniae & 20 & $\mathbf{4 8 , 3}$ \\
Haemophilus influenzae & 10 & 24,4 \\
Staphylococcus aureus & 3 & 7,4 \\
Streptocuccus beta hemolítico grupo A & 1 & 2,4 \\
Staphvlococcus epidermidis & 2 & 4,8 \\
Cultivo negativo & 5 & 12,2 \\
TOTAL & 41 & 100,0 \\
\hline
\end{tabular}

De acuerdo a la edad, la distribución de gérmenes five la siguiente:

Tabla 2

1.3m 3-6m 6-12m 12-24m

\begin{tabular}{lllll}
\hline Streptococcus pneumoniae & 8 & 4 & 6 & 2 \\
Haemophilus influenzae & 2 & 2 & 2 & 4 \\
Staphylococcus aureus & & 1 & 2 & \\
Streptococtus beta hemoli- & & & & \\
$\quad \begin{array}{l}\text { tico grupo A } \\
\text { Staphylococcus epidermidis }\end{array}$ & 1 & 1 & \\
\hline
\end{tabular}

En esta tabla se observa que de las 20 cepas de Streptococeus pneumoniae aisladas, 18 corresponden a lactantes de menos de 1 año de edad y los 6 casos estudiados entre 1 y 2 años, 4 corresponden a Haemophilus influenzae.

Se analizaron algunos parámetros clínicos como, estado nutritivo, temperanura, características de las deposíciones y su relación con esta patologia.

De los 41 pacientes estudiados, 27 (66\%) presentaban deposiciones alteradas en el momento del diagnóstico, interpretándose como diarrea parenteral. En 15 de èstos, se continuó la observación clínica y se comprobó que 11 pacientes $(73,3 \%)$ mejoraron el cuadro diarréico en menos de 72 horas.

Relacionando estado nutritivo y otitis encomtramos la siguiente distribución:

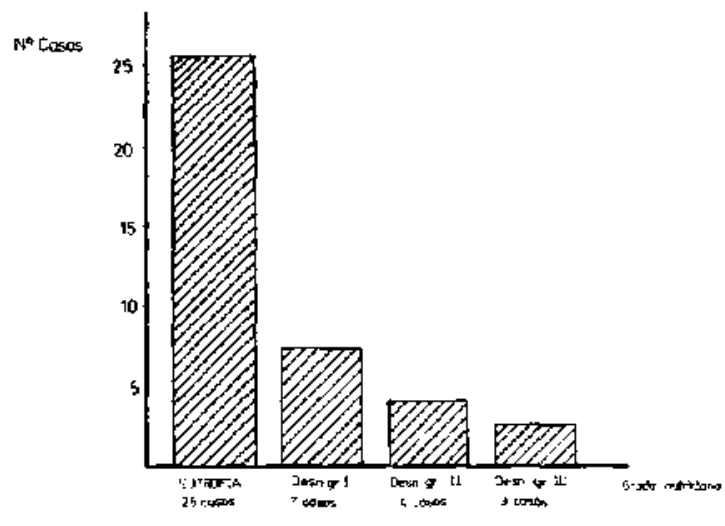

Se observa que la mayoria de los casos, $(63,5 \%)$ se ubica en el grupo eutróficos.

\section{COMENTARIO}

En 41 pacientes estudiados se comprobó etiología bacteriana en $87.2 \%$.

El Streptococcus pneumoniae resulta ser el germen mâs frecuente aislado con un porcentaje de 48,8; encontrándose como primera etiología incluso en los menores de 6 meses.

Hemophilus influenzae se encuentra como segunda frecuencia con un $24,4 \%$, es importante destacarlo por la posible colonización secundaria a partir del foco ótico hacia las meninges.

Staphylococcus epidemidis fue considerado como agente causal ya que ta técnica permitió descartarlo como contaminación. 
Se confinma la otitis media aguda como causa importante de diarrea parenteral.

No se pudo establecer ninguna relación entre casos febriles y gérmenes aislados conno lo demuestran otros estudios que hablan de una estrecha relación entre temperatura sobre $38^{\circ} \mathrm{C}$ y Streptococcus pneumoniae. ${ }^{\prime}$

\section{CONCLUSIONES}

- Streptococcus pneumoniae es el germen más frecuente aislado de otitis media aguda purulenta en lactantes.

- Hemophilus influenzae cobra un papel importante como segunda frecuencia en etiología de otitis.

- Se confirma que la paracentesis es un procedimiento de especialista, está indicado en casos muy específicos y no es necesaria en la práctica pediátrica general.

- Conociendo las posibilidades etiológicas, el pediatra podrá elegir la terapia más racional.

\section{RESUMEN}

Se estudiaron 41 lactantes con el diagnóstico de otitis media aguda. Streptococcus pneumoniae fue el agente mảs frecuente aislado $(48,8 \%)$.
Haemophilus influenzae se aisló como segunda etiología.

La paracentesis está indicada en casos muy específicos y el pediatra general puede prescindir de ella en la mayoria de ellos. Conociendo las posibilidades etiológicas del cuadro se puede elegir una terapia adecuada.

\section{MEFERENCLAS}

${ }^{1}$ Charies, D.; Btuestone, M. D.; Pakt. A.; Shurin, M. D. Middle Ear Disease in Children, pathogenesis, diagnosis and manage. ment. Pediatric Clinics of North America 21: 379-404, 1974.

2 Rowe, D. S. Acute suppurative otitis media. Pediatrics 56 : 285-294, 1975.

${ }^{3}$ Irthak Broak, M. D.; Sidney, M.; Finegold. M. D. Bacteriology of Chronic otitis media. Yama 241: 487-488, 1979.

4 Yock, L.: Paradise, M. O. Otitis media in infents and children. Pediatries 64: 917-941, 1980.

5 Finegald, M.i Klein, J, D.; Hastan, G. E. at od. Acute otitis mediu in children. Am. J. Disease of Children 111: 361, 1066.

6 Coffey, J. D. Jr. Otitis media in the practice of pediatrics. Pediatrics 38: 25, 1966.

7 Nilsan, 8. W.i Poland, R. L.; Thompsor, R. S. et al. Acute otitis media: Treatment results in relation to bacterial etiology. Pediatrics 43: 351, 1969.

8 Howie, V. M.: Plourserd, J. H.: Lester, R. L. Otitis media: A clinical and bacteriological correlation. Pediatrics 45: 29, 1970.

${ }^{4}$ Brook, 1 ; A Anthony, B. F.; Finegold, S, M. Aerobic and angerobic bacteriology of acute otitis medin in children. J. Pediatrics 92 : 13,1978 .

10 Sarah, H, Sell, Md,; David A Wilson. Treatment of otitis media caused by Haemophilus influenzee: Evaluation of three antimicrobial regimens. Southem Medical Joumsl 71:12 1493-1497, Dec. 1978. 